\title{
INFLUENCE OF THE INTERLAMELLAR OXIDE ON THE ELECTROCHEMICAL BEHAVIOR OF FLAME SPRAYED ALLOY 718 COATINGS.
}

\author{
G. Rannou, B. Normand*, P. Berçot, J. Pagetti, C. Coddet* \\ Laboratoire de Chimie des Matériaux et des Interfaces, \\ Université de Franche-Comté, 16 route de Gray, 25030 Besançon Cedex, France. \\ 1 \\ *Laboratoire d'Etudes et de Recherches sur les Matériaux et les Propriétés de Surface, \\ Université de Technologie de Belfort-Montbéliard, BP 449, 90010 Belfort Cedex, France. \\ Institut des Traitements de Surface de Franche-Comté
}

\begin{abstract}
Alloy 718 thermally sprayed coatings are candidates for wide industrial applications. However their morphological defects such as porosity and oxides can hinder their corrosion resistance. High Velocity Oxy-Fuel (HVOF) process was used to decrease the porosity level but interlamellar oxidation remained.

The aim of this work is to highlight the relationship between the thermal spraying parameters and the corrosion resistance of the coatings. The oxidation state of coatings have been identified and quantified by XRD and EDS spectroscopic techniques. Their electrochemical behaviour have been examined in an electrolyte supporting a passive state.

Experimental results show a selective oxidation during the particles flight according to the flame temperature and the energy of the enthalpic source. Interlamellar spinel oxide built up in flight control the electrochemical activation of coatings. Moreover, this oxidation leads to a subsurface chromium depletion in the alloy 718 which weaken the passive state. For economical reasons, other solutions than post-treatments are proposed. These solutions have been tested in order both to limit chromium depletion and to improve coating electrochemical properties.
\end{abstract}




\section{Introduction}

Thermal spray is a surface treatment process which enables the elaboration of thick metallic coatings and complex composition. However, two given ideas on the process limit the applications especially in the field of protection against wet corrosion. In the first place, coatings obtained by spray are considered as porous. The consequence of this is that the use of thermal spray in the anticorrosion field is limited to a cathodic protection of metallic infrastructures. This anticorrosion technique consists in laying on the substrate to protect a material which is electrochemically less noble, called sacrificial anode. In this case, the possible contact between an aggressive media and the substrate, through coating porosity, generates coating corrosion but the substrate remains protected. Thus, infrastructures, usually steel made, are often protected by sprayed coatings of $\mathrm{Zn}$ or $\mathrm{Zn}-\mathrm{Al}[1,2]$. In the second place, when one tries to ensure protection by a barrier layer (for instance stainless steel on steel), porosity appears as a major drawback. The progression of aggressive media up to the substrate could generate its galvanic corrosion. Furthermore, sprayed coatings are known as being usable only after post-treatments such as impregnation by polymeric resins, phosphates or thermal treatments $[1,3]$. On the one hand these post-treatments considerably increase production costs and on the other damage the usage properties of the sprayed materials.

In the study, we aim at elaborating by thermal spray a stainless type coating with no posttreatment. This implies first the creation of coatings barriers, with no or very little porosity in order to avoid any galvanic corrosion risk. Among the many thermal spray processes, the High Velocity Oxy-Fuel (HVOF) appears as the most adapted for obtaining dense deposits. With a HVOF spraying torch, the combustion of oxygen and fuel provokes a supersonic speed flame in which the particles of sprayed material are melted and accelerated. Then, these particles strike the substrate to solidify and so build the deposit. The characteristic of this process is the high speed of the particles $\left(500-1200 \mathrm{~m}^{-1} \mathrm{~s}^{-1}\right)$ which helps in the coating densification [1] and also a fairly low flame temperature compared to plasma processes $\left(5300^{\circ} \mathrm{C}\right.$ vs. $\left.12000^{\circ} \mathrm{C}\right)$ [4]. Together with porosity limitation, the creation of stainless type coatings demands control of the sprayed material composition. Resistance to corrosion of stainless type materials depends for the most part on their composition. But sprayed alloy may successively be oxidized when flying through the flame, to the substrate, and solidifying on it. Although, oxidation time is short ( $\approx 1 \mathrm{~ms}$ flight inside the flame and outside the flame, $10-20 \mathrm{~ms}$ on the substrate) [5], oxidation is particularly marked because of particle temperature and spraying atmosphere.

There are two potential consequences to this oxidation phenomenon. First, oxides, mostly shared among metallic splats, represent chemical and mechanical heterogeneity in metallic coatings. These interlamellar oxides are even known as preferential sites for electrochemical attack [6]. Aggressive media advances towards the substrate by this oxide chemical dissolution which promotes discohesion of coating. Besides, the alloy oxidation may lead to selective oxidation because of the discrepancy of diffusion between alloy components. This process may lead to a notable change in oxidized surface composition, especially for high-alloy steels.

Consequently, when choosing the material, the usage properties of the coatings need taking into account, i.e. their stainless characteristic, and the elaboration constrains, such as particle oxidation. Stainless steel having poor oxidation resistance, spraying this type of alloy often leads to coatings with modified electrochemical properties. Moreover, the oxide scales growing on stainless steel are poorly adhesive which limits interlamellar cohesion in the sprayed coating. Among stainless type alloys, alloy 718 seems for its part to fulfill selection criteria. In aqueous media, its chromium content favors the formation of a protecting layer of oxi- 
hydroxide corresponding to the passive film. This property grants it efficient wet corrosion resistance [7]. Moreover, under high temperature, the oxidation kinetic is fairly slow and the scale formed on the superalloy is chromium-rich (oxide $\mathrm{Cr}_{2-\mathrm{X}} \mathrm{M}_{\mathrm{X}} \mathrm{O}_{3}$ or spinel) [8]. These oxides present a very high adhesion to the metallic material which favors the interlamellar cohesion of alloy 718 coatings.

This study aims at identifying the effect of HVOF process on the electrochemical behavior of alloy 718. This characterization has for objective to evaluate the wet corrosion resistance of thermally sprayed coatings and show the interest of the alloy 718 requirement through electrochemical characterization. These analyses have been correlated to the modifications due to oxidation of sprayed material. These modifications are also analyzed by spectrometric techniques (EDS and XRD). Finally, in order to obtain by thermal spraying coatings presenting strong corrosion resistance several elaboration parameters have been tested.

\section{Experimental Procedure}

Thermally sprayed coatings have been elaborated with gas-atomized alloy 718 powder (Sulzer Metco) (Figure 1) using a HVOF CDS type torch distributed by Sulzer Metco.

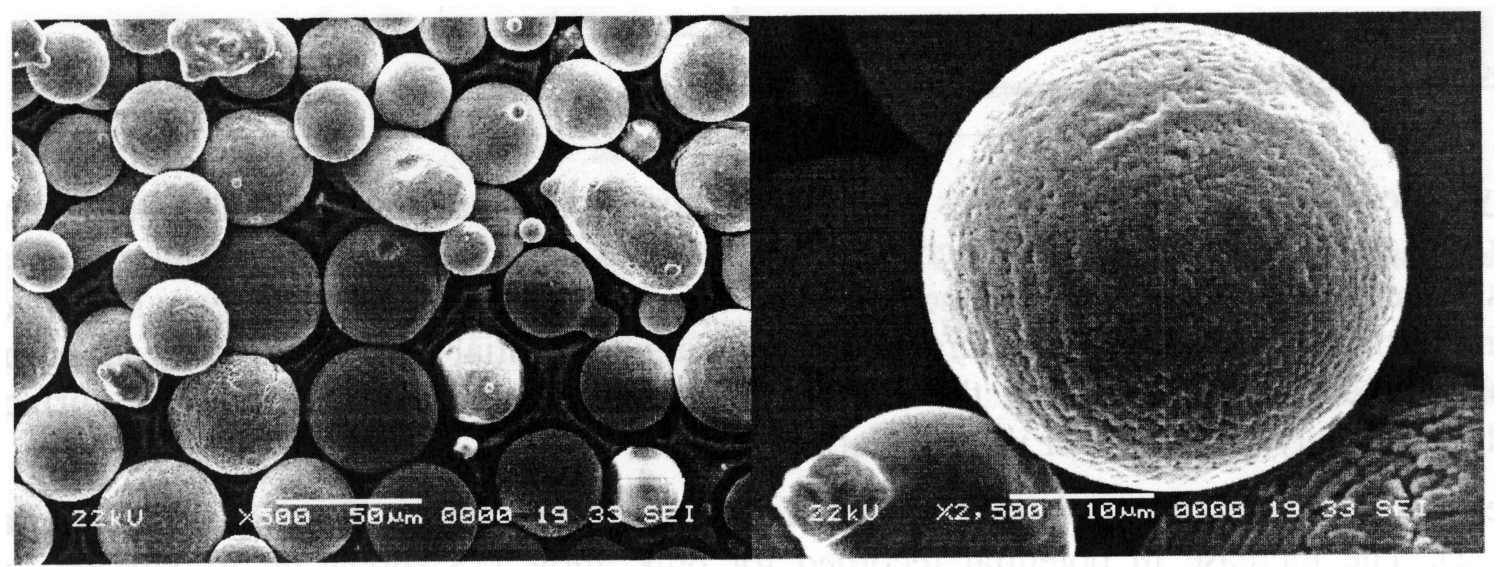

Figure 1 : Alloy 718 gas-atomized powder

The coatings are prepared with three power levels; the spraying power depending on the fuel and oxygen flow (Table I). These 3 coatings are sprayed on aluminum and stainless steel $316 \mathrm{~L}$ sand blasted substrates of dimension $80 * 50 * 3 \mathrm{~mm}^{3}$.

Table I : Spraying parameters

\begin{tabular}{lccc}
\hline Ref. & $\boldsymbol{A}$ & $\boldsymbol{B}$ & $\boldsymbol{C}$ \\
\hline $\mathrm{O}_{2}(\mathrm{~N} l / \mathrm{min})$ & 396 & 324 & 288 \\
$\mathrm{CH}_{4}(\mathrm{Nl} / \mathrm{min})$ & 220 & 180 & 160 \\
Power $(\mathrm{kW})$ & 85 & 70 & 61 \\
\hline
\end{tabular}

Alloy 718 coatings are electrochemically characterized in a $\mathrm{H}_{2} \mathrm{SO}_{4}, 2 \mathrm{~N}$ solution, de-aerated and thermostated at $21^{\circ} \mathrm{C}$. The electrochemical measurements are made with a standard three- 
electrode apparatus. All potentials are referred to a saturated mercurous sulfate electrode (SSE). The solution and this electrode are linked by a salt bridge containing a highly diluted potassium sulfate solution (3\%). As-sprayed coatings are wrapped in an adhesive in which a work frame is cut. Lacquer is also coated round the frame in order to avoid crevice corrosion. The surface as defined is of $16 * 10 \mathrm{~mm}^{2}$. We apply an average corrective factor of $125 \%$, obtained by measuring surface roughness. So, the true surface of the electrode is of $2 \mathrm{~cm}^{2}$.

Electrochemical measurements are divided into 2 parts. First, we record the evolution of free potential for $6000 \mathrm{~s}$. These results enable the drawing of the $E=f(t)$ curves. We then conduct a potentiodynamic scanning between $-1000 \mathrm{mV}$ and $+600 \mathrm{mV}$ at $1 \mathrm{mV} . \mathrm{s}^{-1}$ speed. A Radiometer type PGP201 potentiostat imposes potential difference between working electrode and reference electrode. This electrochemical procedure is validated by checking the reproducibility of results concerning bulk alloy 718 electrodes.

For SEM observations and EDS analysis, the coatings are transversally cut, then hot mounted in conductive thermosetting resin. The samples are then polished till $0.3 \mu \mathrm{m}$ granulometry. So, the powder is hot mounted, then prepared according to the same procedure as used for the deposits. The microstructure of the as-sprayed coatings and the powder is examined by XRD. Coatings composition, and particularly oxygen content, is analyzed by EDS with a XPP type correction [9]. This analytic procedure is paired with a JEOL JSM-5600 type scanning electron microscope.

\section{Results}

\section{Electrochemical behavior}

Porosity. The development of coatings based on a more noble material than substrate means making sure they remain tight in an aggressive media. Measuring the evolution of free potential appears to be a particularly accurate means to test this property of coatings. Indeed, if contact between electrolyte and substrate occurs, the tested coating potential will immediately adopt the less noble potential characterizing the substrate. Moreover, whatever the substrate surface reached by electrolyte, the answer in potential is observed.

The free potential evolution of sprayed coatings appears different to that of bulk material (Figure 2). The increase in potential recorded for bulk alloy 718 shows on its surface the development of a passive film. The latter provides the alloy with a good resistance to electrochemical corrosion .

As for coatings, two steps can be noticed whatever the spraying conditions. The first step is characterized by a fairly low potential evolution up to $-250 \mathrm{mV}$. The length of this step is linked to spraying parameters. Thus, the spraying power increase implies its significant increase in time (Figure 3). One may also point out that this lengthening is much stronger for stainless steels substrates. The first step seems to be linked to the oxidation state of the sprayed material. When oxidation is favored (strong power) this step tends to lengthen. Noticeably, increase of this spraying parameter also favors a greater densification of the deposits. Substrate effect tends to confirm the role of oxides. Thus, alloy 718 sprayed on stainless steel cools down less quickly than the one developed on aluminum because of the different thermal properties of these materials. This slower cooling promotes stronger oxidation and consequently lengthening of the initial step. 


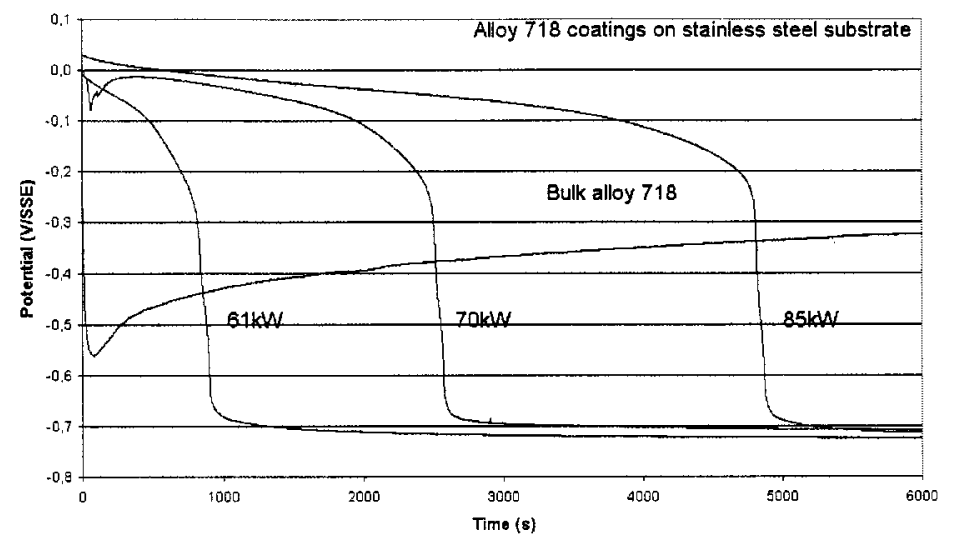

$\mathbf{a}$

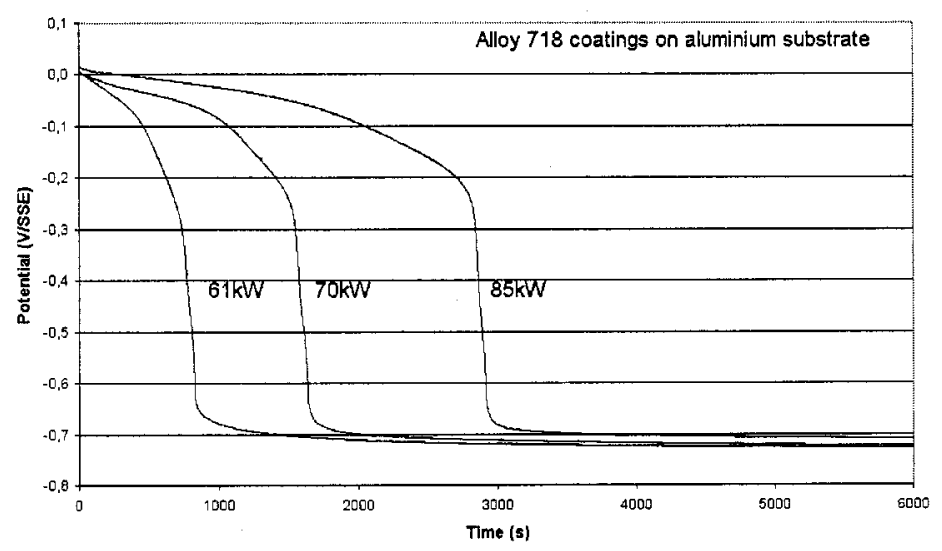

b

Figure 2 : Free potential of bulk alloy 718 and HVOF coatings on stainless steel substrate (a), HVOF coatings on aluminum substrate (b).

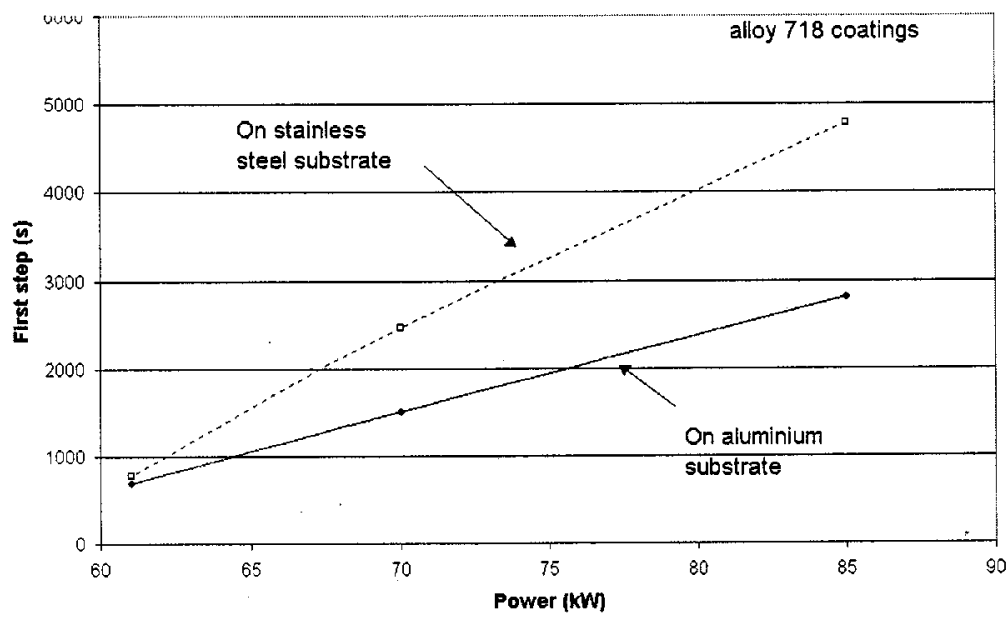

Figure 3 : First step versus spraying power for HVOF coatings on stainless steel $(--)$ and aluminum (-) substrates. 
After this first step, the potential collapses and ends up stabilizing around $-710 \pm 10 \mathrm{mV}$. This last potential does not vary according to substrate type. Yet, we know that stainless steel and aluminum bear very different electrochemical behaviors [10]. Therefore, this result proves that substrate is not concerned by electrochemical reactions and coatings form a real protecting barrier.

Oxidation. Potentiodynamic polarization curves show a change in composition of the material due to thermal spray. Indeed, the coatings passivation process is defined by a double current peak unlike the bulk material (Figure 4). By studying the electrochemical behavior of bulk nickel (99.99\% purity), we also record a double passivation peak which is usually attributed to the development of nickel hydroxide adsorbed film (first peak) then to its transformation into a passive film of oxy-hydroxide type (second peak) $[11,12]$.

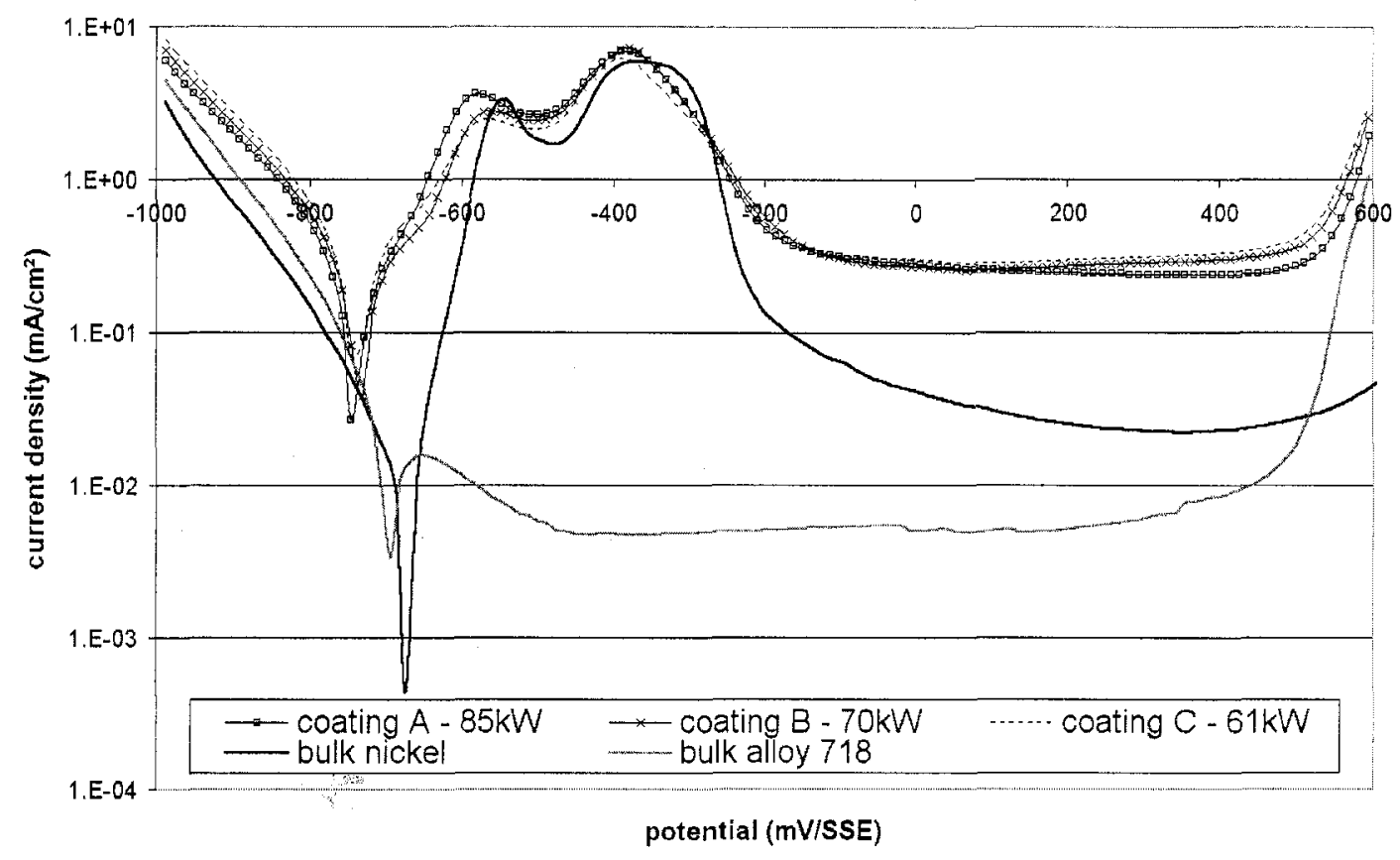

Figure 4 : Potentiodynamic polarization curves of bulk alloy 718 , bulk nickel and HVOF alloy 718 coatings on stainless steel.

Passivation ability of the coatings is defined by the study of the activation peak. Potential of these peaks $\left(E_{1}, E_{2}\right)$ characterize electrochemical reactions leading to passive film formation. Whatever the type of substrate, the potentials are similar (Table II). This fact confirms the non-attainment of substrate by electrolyte: Moreover, the potential shift compared with bulk nickel shows the influence of alloying elements.

Concerning current densities of activation peaks, Normand [13] has established that the lower they are, the better is the passivation ability. In table II, a decrease in spraying power enhances the ability of passivation. As gas speed and temperature of the HVOF flame is conditioned by power level, a lower power induces a lower oxidation of sprayed particles. So, a lower oxidation leads to a better passivation ability of the sprayed materials due to an attenuated composition change. Spectrometric analysis is needed to quantify this composition change. One may also notice that the power has greater influence on the first current peak $\left(i_{1}\right)$, attributed to the formation of an adsorbed hydroxide layer, than on the second one. 
Table II : Electrochemical criteria for bulk and HVOF coatings of alloy 718.

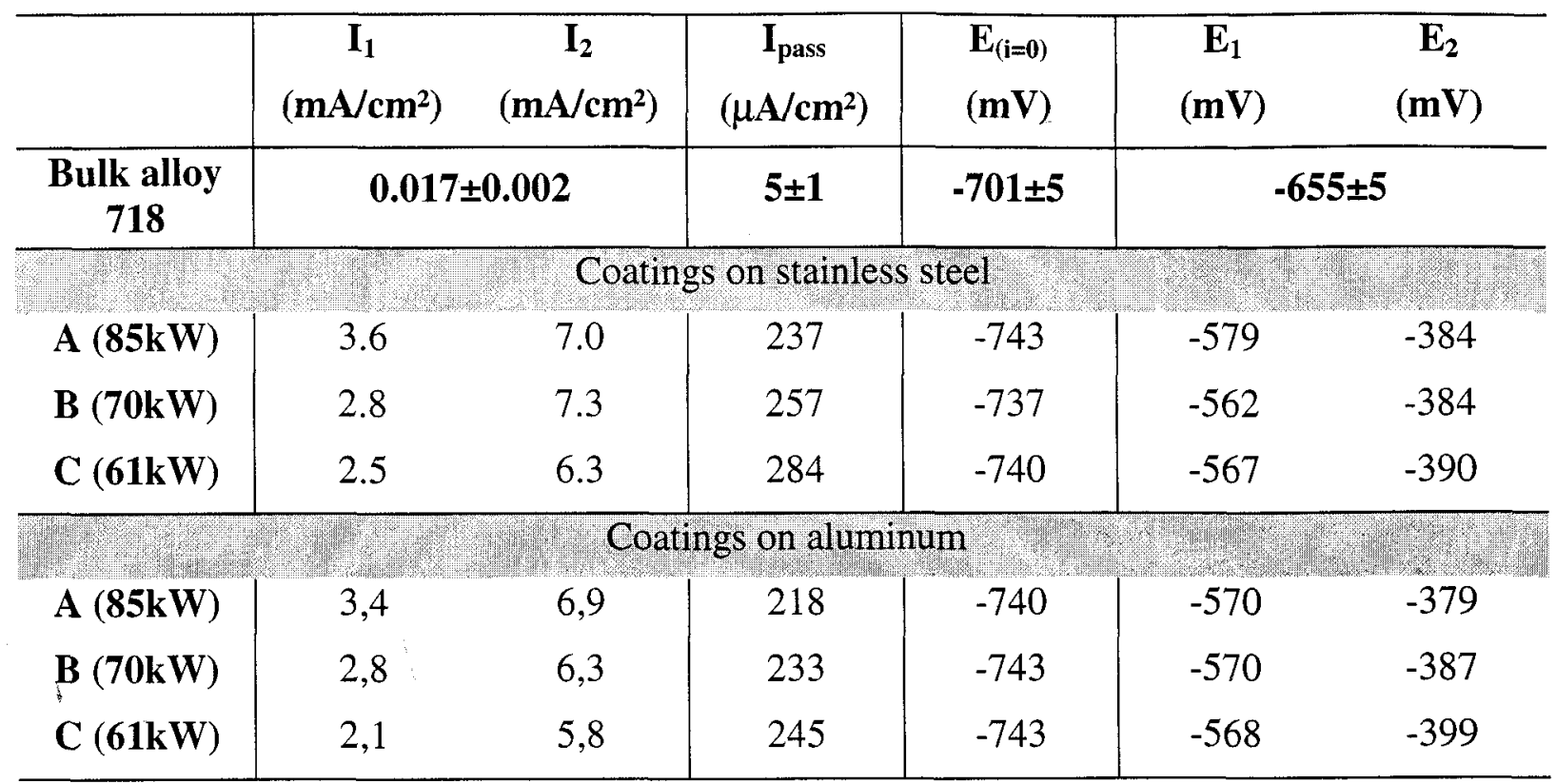

Finally, passive current density, $\mathrm{i}_{\text {pass, }}$, representative of passive film homogeneity can be considered as equivalent and differences among coatings are inherent in coating density (Figure 5).

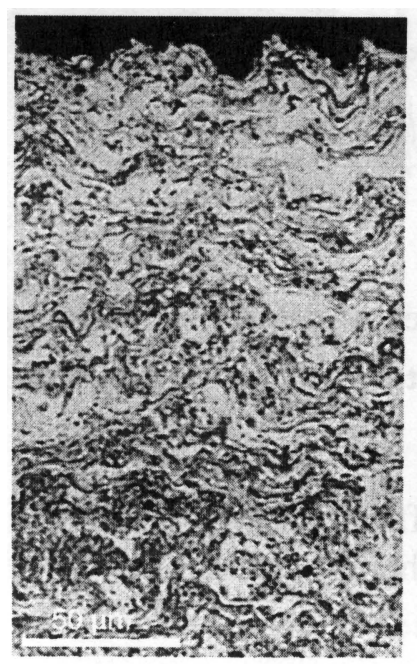

Coating A - 85kW

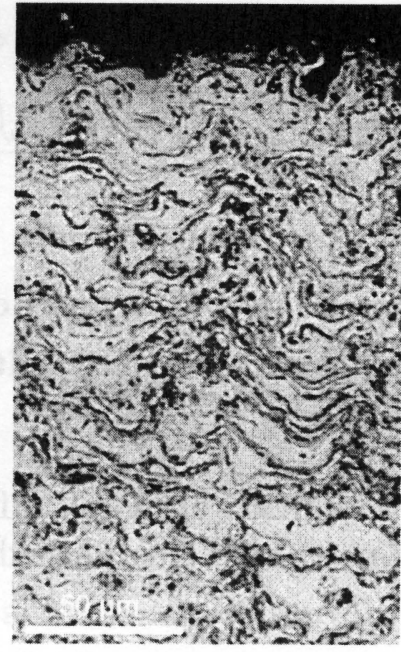

Coating B - 70kW

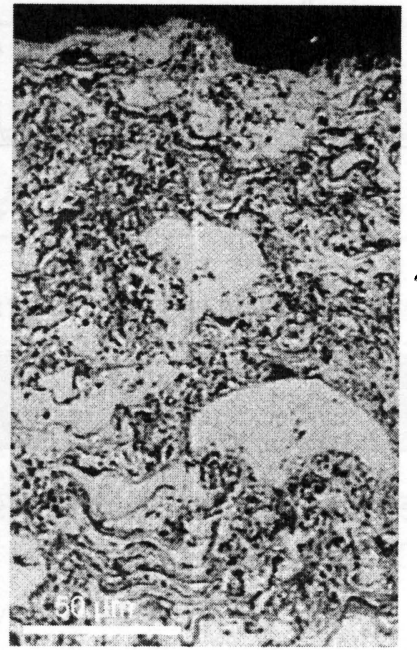

Coating $\mathrm{C}-61 \mathrm{~kW}$

Figure 5 : Cross-sections of HVOF alloy 718 coatings.

Given the incidence of oxidation on electrochemical behavior, we have undertaken the characterization of this oxidation. 
The powder bears the classical crystallographic structure of a thermally untreated alloy 718 . Phase $\delta$ is revealed by X-ray diffraction (Figure 6). In the coatings, these components only appear in unmelted particles. Some titanium and niobium carbonitrides can also be observed both in the powder and in the deposits.
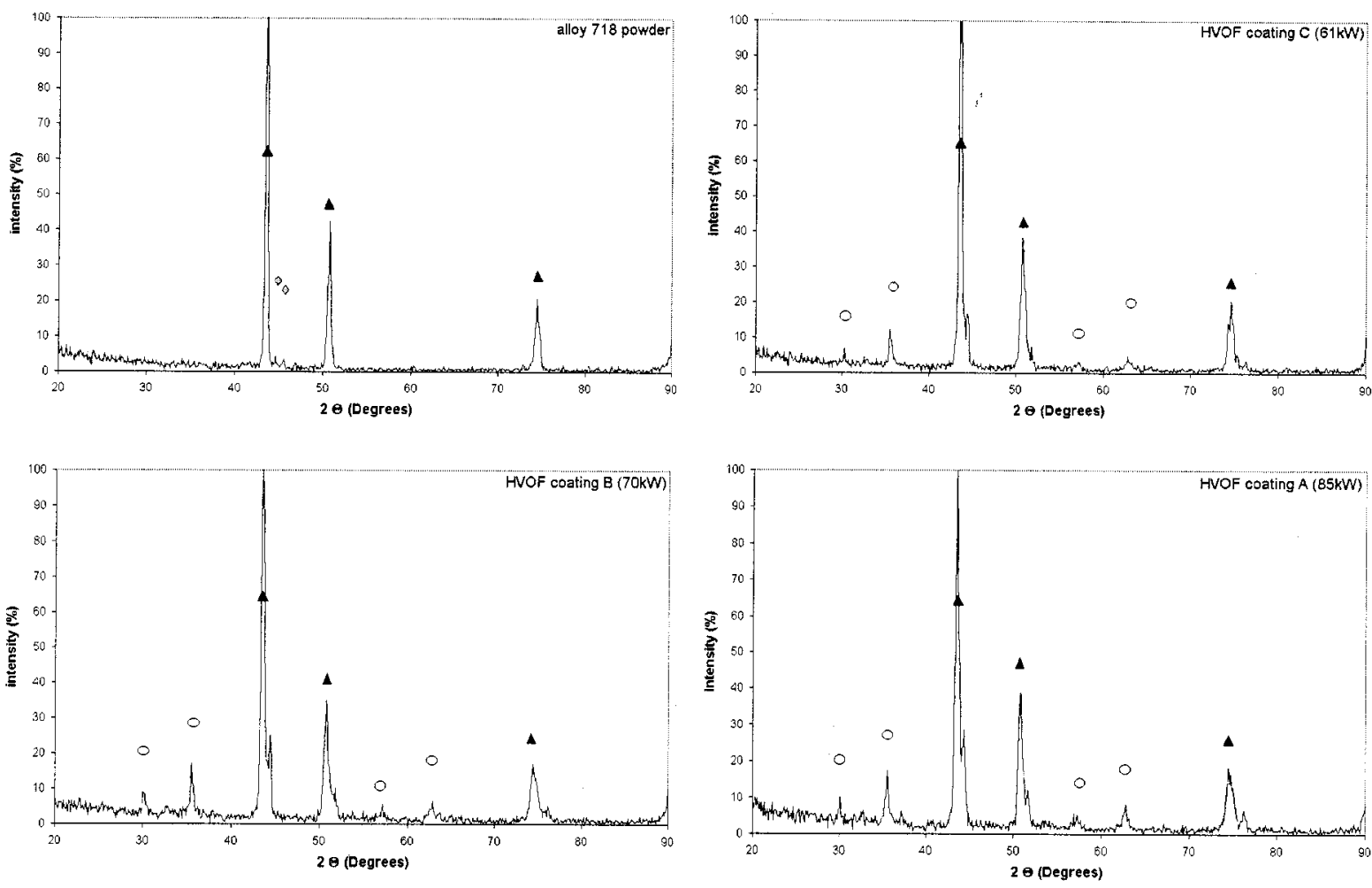

Figure $6:$ X-ray diffractogram of alloy 718 powder and HVOF coatings on aluminum substrate ( $\Delta:$ fcc phase, $\diamond$ : delta phase, $O:$ spinel)

The presence of oxide in coatings is identified by X-ray diffraction as a $\mathrm{FeCr}_{2} \mathrm{O}_{4}$ (ASTM 341272) or $\mathrm{NiCr}_{2} \mathrm{O}_{4}$ (ASTM 23-1272) type spinel. One must therefore consider an ( $\left.\mathrm{Fe}, \mathrm{Ni}\right) \mathrm{Cr}_{2} \mathrm{O}_{4}$ type oxide.

A semi-quantitative analysis of the oxygen element is led by EDS (Figure 7). Each point on the graph corresponds to an average of the results obtained on 20 squares of $180 \mu \mathrm{m}^{2}$. On the one hand this analysis reveals that oxidation increases quasi-linearly with spraying power and on the other that the substrate influence does not appear so significant.

It is known that alloy 718 when oxidizing may undergo a change in composition because of the selective oxidation of alloying elements [8]. In order to check the effects of oxidation on sprayed alloy 718 , we undertake a linear analysis of composition by EDS through a splat (Figure 8). The results show the presence of a chromium depleted zone subjacent to interlamellar oxide. 


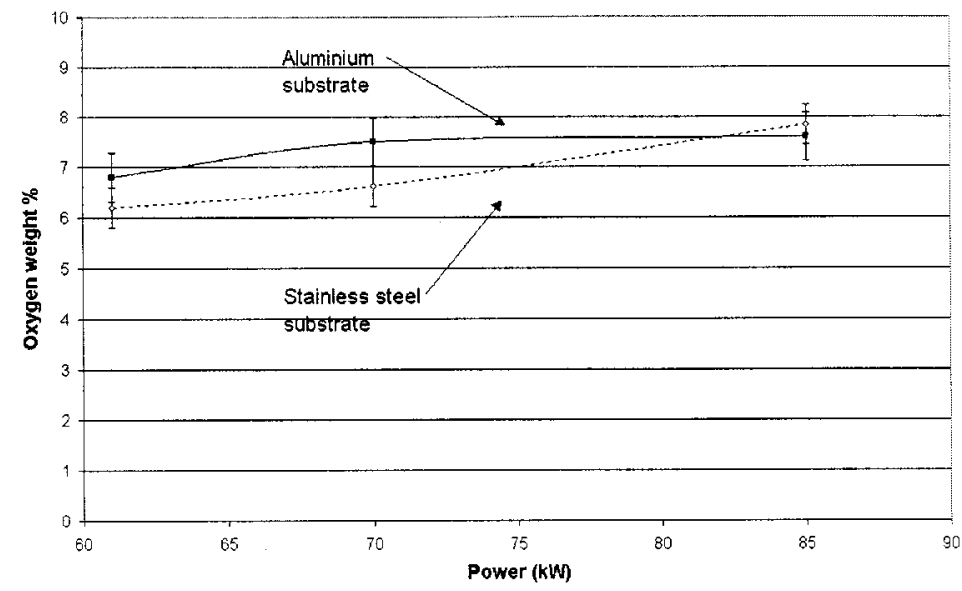

Figure 7 : Oxygen content versus spraying power

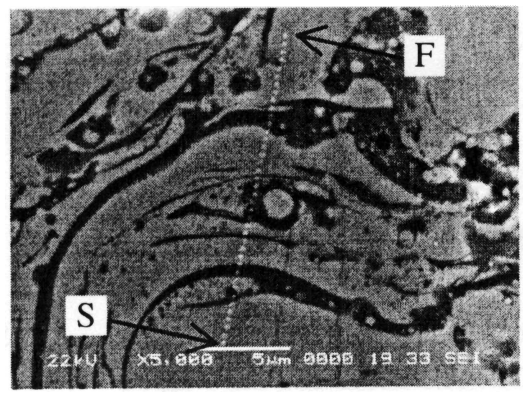

coating A on stainless steel

(substrate is on the left)

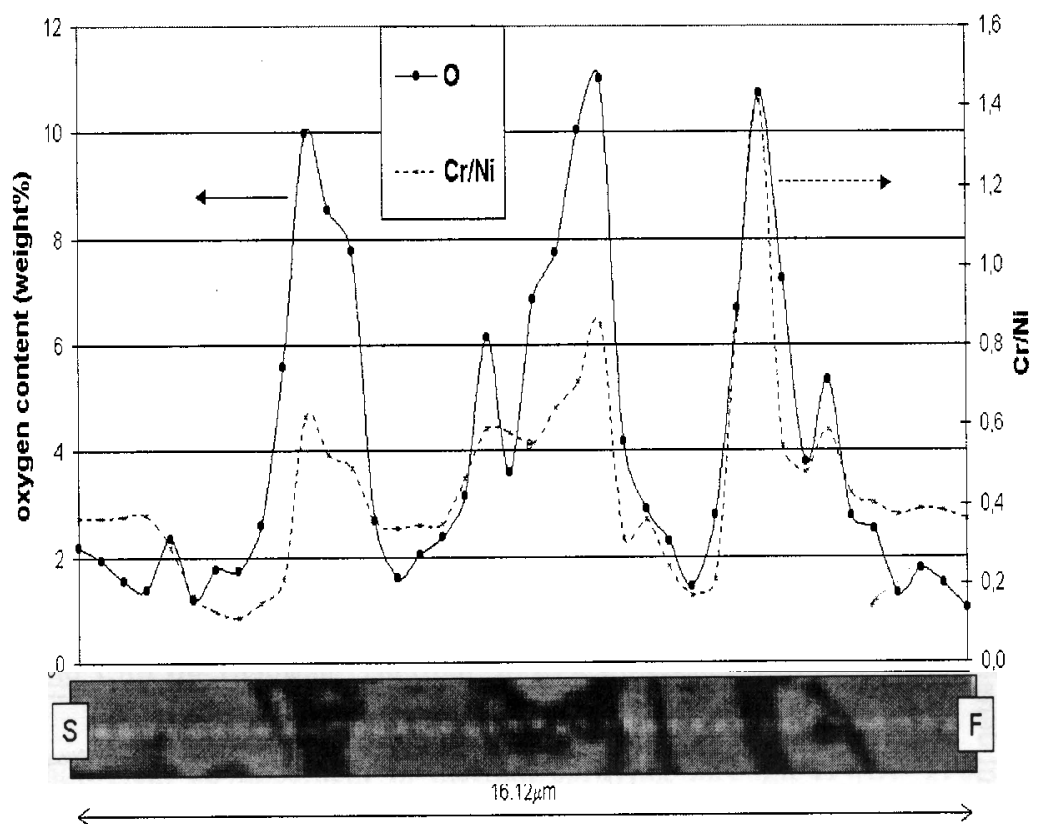

Figure 8 : EDS linescan analysis on alloy 718 HVOF coating

\section{Discussion}

Electrochemical tests have first revealed coating density which is defined by the evolution of free potential. It is hence proven that HVOF spraying enables the development of barrier metallic coatings without post-treatments. Many applications in the field of anticorrosion become open to the HVOF spraying of such an alloy.

Then, electrochemical and spectroscopic analyzes bring to light an oxidation inherent to thermal spraying. This phenomenon has 2 consequences. First, an oxide film develops on the surface of alloy 718 which is identified as a spinel $(\mathrm{Fe}, \mathrm{Ni}) \mathrm{Cr}_{2} \mathrm{O}_{4}$. These interlamellar oxides play an important part in the penetration of aggressive media towards sprayed metallic material. 
In the $E=f(t)$ curves, a first step defining this permeation is identified. The length of this step and with it the electrolyte progression speed seem to depend on the quantity of oxide in the deposit and the type of substrate. Substrate influence may be explained through the thermal properties of stainless steel and aluminum. It is supposed that the cooling of sprayed particles is faster on aluminum than on stainless steel. Yet, a fast cooling exacerbates stresses between the oxidized material and its oxide [14]. These thermal stresses may lead to the cracking of the oxide scale or its discohesion from the subjacent metal. These discohesions accelerate electrolyte penetration towards sprayed alloy 718 . We may also take into account mechanical properties of the substrate.

Under oxide scale, alloy 718 is severely chromium depleted. Consequently, a deterioration in the material passivation ability can be observed. This change in composition is due to a preferential chromium oxidation process. The electrochemical behavior of the coatings must then be compared to that of nickel, the main constituent of the alloy.

In this context, one may consider improving electrochemical performances by increasing the chromium content of the sprayed alloy in order to master the effects of selective oxidation. To validate this hypothesis, we have undertaken the HVOF spraying of a nickel-based superalloy, alloy 690 which initial chromium content is situated between $27-31 \%$ (Ni : 58-63\%, Fe : 7$11 \%$ ). As shown in figures 9 , an increase in chromium content enables an electrochemical reactivity close to bulk alloy 718 .

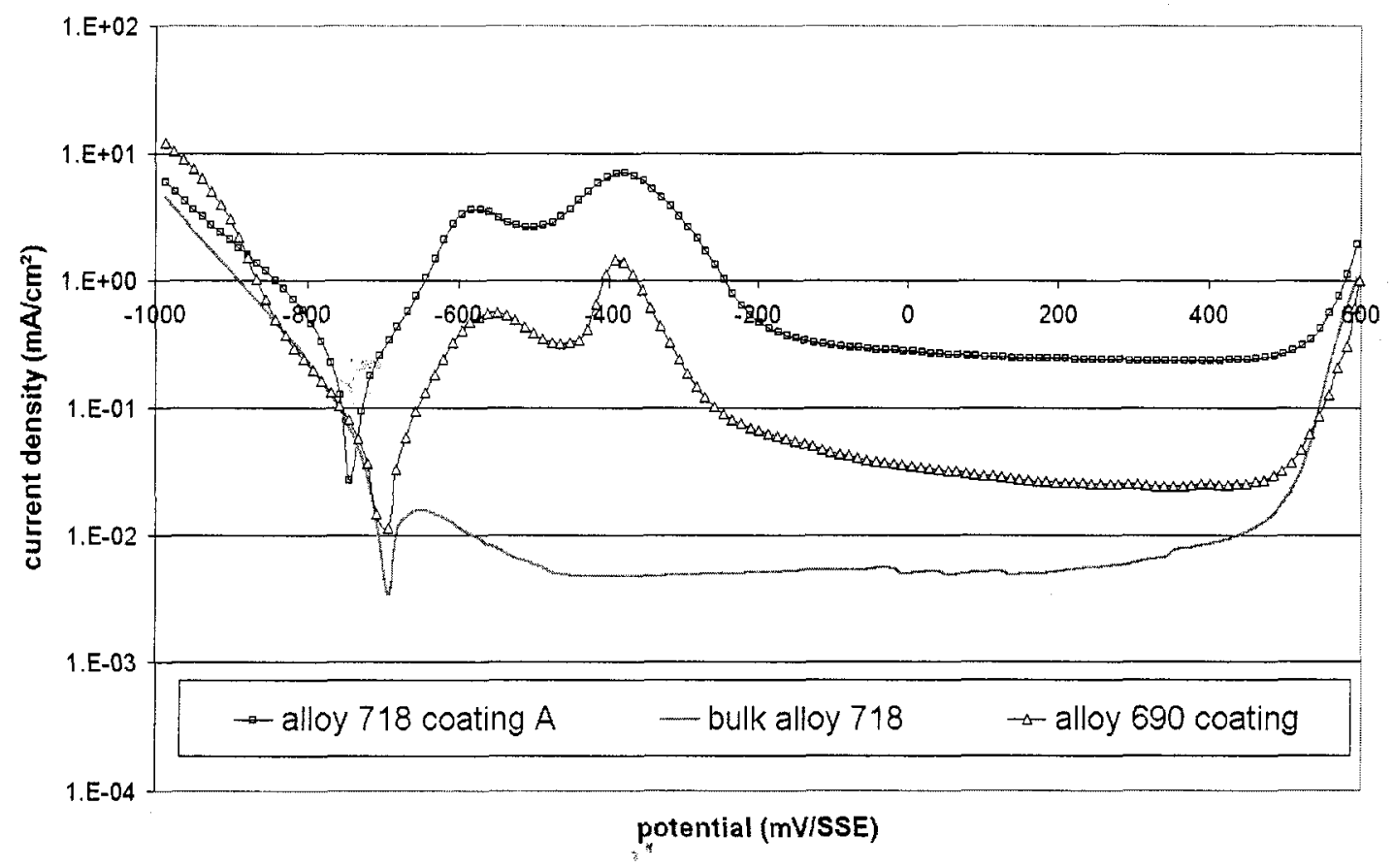

Figure 9 : Potentiodynamic polarization curves of HVOF alloy 690 coating, alloy 718 coating $A$ and bulk alloy 718 . 


\section{Conclusion}

This study has shown that the development by thermal spraying of dense coatings bearing anticorrosion properties is possible without using post-treatments. This has been possible thanks to the use of superalloys such as 718 , or even 690 . Substrate integrity has been unquestionably verified by electrochemical means. It has also brought to light the role of interlamellar oxides in the progression of corrosive media towards sprayed material. Speed of progression depends both on oxide quantity (linked to spraying power) and the state of cohesion of these interlamellar oxides (according to substrate type). Together with the development of the spinel (Fe, $\mathrm{Ni}) \mathrm{Cr}_{2} \mathrm{O}_{4}$, one may observe a chromium depletion in the interlamellar zone. This change in composition significantly reduces the electrochemical performances of the sprayed superalloy and more particularly its passivation ability.

Nevertheless, as shown in the results obtained for alloy 690 coatings, an increase of the chromium content in the sprayed powder noticeably improves the coatings electrochemical performances. These last results pave the way for new applications concerning nickel-based superalloys. Further activity may be envisaged to determine the optimal composition of a particular grade of alloy 718 specifically designed for thermal spraying. Now works are also in progress to identify precisely the nature and the morphology of the interlamellar oxidation.

\section{References}

1. S. Tobe, "A review on protection from corrosion, oxidation and hot corrosion by thermal spray coatings," Proceedings of the 15th International Thermal Spray Conference, ed. C. Coddet, Nice, France, 1998, 311.

2. J.S. Tinnea, "Field performance of sprayed zinc cathodic protection anodes," Proceedings of the 15th International Thermal Spray Conference, ed. C. Coddet, Nice, France, 1998, 37-42.

3. K. Sridhar, A.S. Khanna, and M.B. Deshmukh, "Formation of highly corrosion resistant alloys using laser surface alloying," Proceedings of the 15th International Thermal Spray Conference, ed. C. Coddet, Nice, France, 1998, 43-48.

4. D. Kumar and S.C. Modi, "Technological advancement in thermal spraying through HVOF Process," Trans. Metal Finisher's Association of India, 1995 (4) (1), 43-48.

5. K. Dobler, H. Kreye, and R. Schwetzke, "Oxidation of stainless steel in the high velocity oxy-fuel process," J. of Thermal Spray Technology, 2000 (9) (3), 407-413.

6. B. Normand et al., "Corrosion resistance of thermal spray Inconel 690 coatings," Proceedings of the 15 th International Thermal Spray Conference, ed. C. Coddet, Nice, France, 1998, 69-73.

7. R. Radovici and I. Roman, "Influence des éléments d'alliage sur le comportement du Nickel et des superalliages à base nickel," Rev. Chim., 1997 (48) (1), 45-52.

8. F. Delaunay et al., "SEM-EDS and XPS studies of the high temperature oxidation behaviour of inconel 718," Mikrochimica Acta, 2000 (132), 337-343.

9. J.L. Pouchou, "Standardless X-Ray Analysis of Bulk Specimens," Mikrochimica Acta, 1994 (114/115), 33-52.

10. M. Pourbaix, Atlas d'équilibres électrochimiques à $25^{\circ} \mathrm{C}$ (Paris, Gauthier-Vilars, 1963).

11. J.R. Vilche and A.J. Arvia, "Kinetics and mechanism of the nickel electrode- II - Acids solutions containing a high concentration of sulphate and nickel ions," Corr. Sci., 1978 (18), 441-463.

12. C.F. Zinola and A.M. Castro Luna, "The inhibition of $\mathrm{Ni}$ corrosion in $\mathrm{H}_{2} \mathrm{SO}_{4}$ solutions containing simple non-saturated substances," Corr. Sci., 1995 (37) (12), 1919-1929. 
13. B. Normand, A. Pierre, and J. Pagetti, "Electrochemical and surface studies of the passive layers grown on sputter-deposited nitrogen-stainless steel alloys in $1 \mathrm{M} \mathrm{H}_{2} \mathrm{SO}_{4}$ solution," 1997 (37) (10), 1537-1549.

14. S.J. Bull, "Modelling of residual stress in oxide scales," Oxidation of metals, 1997 (49) (1/2), 1-17. 